\title{
Narp Mediates Antidepressant-Like Effects of Electroconvulsive Seizures
}

\author{
Andrew D Chang', Punit V Vaidya', Edward P Retzbach', Sunho J Chung', Urian Kim', Kathryn Baselice', \\ Kristen Maynard', Alec Stepanian', Melissa Staley', Lan Xiao', Ashley Blouin', Sungho Han', JongAh Lee', \\ Paul F Worley', Kellie L Tamashiro', Barbara L Hempstead ${ }^{3}$, Keri Martinowich ${ }^{1,2}$, Mary Ann Wilson ${ }^{1,4}$, \\ Jay M Baraban' and Irving M Reti*,I
}

'The Johns Hopkins University School of Medicine, Department of Psychiatry and Behavioral Sciences, Baltimore, MD, USA; ${ }^{2}$ Lieber Institute for Brain Development, Baltimore, MD, USA; ${ }^{3}$ Weill Cornell Medical College, Department of Medicine, New York, NY, USA; ${ }^{4}$ The Kennedy Krieger Institute, Baltimore, MD, USA

\begin{abstract}
Growing recognition of persistent cognitive defects associated with electroconvulsive therapy (ECT), a highly effective and commonly used antidepressant treatment, has spurred interest in identifying its mechanism of action to guide development of safer treatment options. However, as repeated seizure activity elicits a bewildering array of electrophysiological and biochemical effects, this goal has remained elusive. We have examined whether deletion of Narp, an immediate early gene induced by electroconvulsive seizures (ECS), blocks its antidepressant efficacy. Based on multiple measures, we infer that Narp knockout mice undergo normal seizure activity in this paradigm, yet fail to display antidepressant-like behavioral effects of ECS. Although Narp deletion does not suppress ECS-induced proliferation in the dentate gyrus, it blocks dendritic outgrowth of immature granule cell neurons in the dentate molecular layer induced by ECS. Taken together, these findings indicate that Narp contributes to the antidepressant action of ECT and implicate the ability of ECS to induce dendritic arborization of differentiating granule cells as a relevant step in eliciting this response.

Neuropsychopharmacology (2018) 43, I088-1098; doi:I0.1038/npp.2017.252; published online 29 November 2017
\end{abstract}

\section{INTRODUCTION}

Depression is a growing problem worldwide and $30 \%$ of patients do not adequately respond to existing pharmacologic treatment (Rush et al, 2006a). As a result, electroconvulsive therapy (ECT), which is the most effective and has the most rapid onset of all FDA-approved therapies available for treatment-resistant depression (Segman et al, 1995; Husain et al, 2004; Rush et al, 2006b), is widely used despite its limitations, including the requirement for repeated anesthesia and development of significant cognitive side effects. These drawbacks have stimulated interest in identifying the molecular mechanisms mediating ECT's antidepressant action to guide development of improved treatment regimens, a daunting challenge given the wide ranging effects of repeated seizure activity on biochemical signaling pathways in neurons and glia throughout the brain.

As multiple immediate early genes are rapidly and robustly induced by electroconvulsive seizures (ECS) (Cole et al, 1990) and have been shown to play key roles in enduring forms of synaptic plasticity (Xiao et al, 2000; Shepherd et al,

* Correspondence: Dr IM Reti, Psychiatry and Neuroscience, Johns Hopkins University, 600N. Wolfe St, Meyer 3-181, Baltimore, MD 21205, USA, Tel: +I 410955 |484, Fax: + 410955 0I52, E-mail: imreti@jhmi.edu

Received 22 April 2017; revised II October 2017; accepted 15 October 2017; accepted article preview online 20 October 2017
2006), we considered the possibility that this transcriptional response could contribute to the long-lasting antidepressant effect of ECT. In exploring this hypothesis, we chose to focus on Narp (Tsui et al, 1996a), an immediate early gene induced by ECS, for several reasons: (1) Glutamatergic dysregulation has been implicated in the pathophysiology of depression (Krishnan and Nestler, 2008), and Narp, which is secreted from pre-synaptic terminals (Reti et al, 2002a, 2008b), regulates AMPA receptor clustering (O'Brien et al, 1999). (2) Narp plays a key role in BDNF-dependent synaptic modulation (Mariga et al, 2015), and BDNF regulates antidepressant responses (Castren and Rantamaki, 2010a). (3) Narp is expressed in multiple afferents to the nucleus accumbens (NAc; Johnson et al, 2010a), a key regulator of mood. (4) Unlike most other immediate early gene products induced by ECS which show transient increases in protein levels following ECS, Narp protein stays elevated for nearly $24 \mathrm{~h}$ and accumulates in the hippocampus with repeated ECS (Reti and Baraban, 2000). To test the role of Narp in mediating the antidepressant effects of ECT, we evaluated the effect of repeated ECS or sham treatment on the performance of Narp KO and WT mice on the forced swim test (FST) and tail suspension test (TST), widely used measures of antidepressant efficacy (Cryan et al, 2005; Petit-Demouliere $e t$ al, 2005). In addition, we assessed whether Narp deletion impairs biochemical or histological responses that have been linked to ECS-mediated antidepressant action. 


\section{MATERIALS AND METHODS}

\section{Animals}

Since repeated ECS treatments have a high rate of mortality in many mouse strains commonly used for behavioral studies (Torchiana and Stone, 1959), we generated Narp KO mice (Johnson et al, 2007) on a CF-1 background, as this strain withstands repeated ECS well. There is no evidence that this strain has altered pain sensitivity that could affect strain response on FST and TST (Gebhart and Mitchell, 1973; Seale et al, 1996). Narp KO mice were backcrossed to the outbred CF-1 strain (Charles River, Wilmington, MA) for five generations. WT and $\mathrm{KO}$ mice on a CF-1 background were generated by breeding Narp heterozygotes. Male CF-1 mice aged 8-12 weeks (25-45g) were used for all the experiments. With the exception of mice undergoing chronic stress, mice were housed 2-5 per cage, in a mouse-only animal room maintained at $71 \pm 4^{\circ} \mathrm{F}, 23-48 \%$ humidity, and under a $12: 12 \mathrm{~h}$ light:dark cycle, with lights on at 0500 hours. Unless otherwise stated, mice had ad libitum access to food and water, and behavioral experiments took place between 0900 hours and 1500 hours. Prior to experimentation, mice were acclimatized to the animal room for a minimum of 2 weeks and handled for at least 3 days. All experiments were approved by The Johns Hopkins University Animal Care and Use Committee.

\section{Electroconvulsive Seizure}

Electrical pulses used to induce ECS were administered using padded earclip electrodes soaked in saline. Pulse trains were generated by a rodent electroconvulsive device (ECT Unit model 57800; Ugo Basile, Collegeville, PA) and set to the following parameters for all treatments: $0.5 \mathrm{~ms}$ pulse width, $1 \mathrm{~s}$ stimulus duration, frequency of $100 \mathrm{~Hz}$, and current of $40 \mathrm{~mA}$ (Chang et al, 2016). The stopwatch was started as soon as the stimulation train stopped. All mice treated with ECS exhibited a tonic-clonic seizure lasting approximately 20 s. Sham ECS was performed by attaching saline-soaked earclips to the mice but without passing any current. All courses of ECS consisted of five daily treatments as preliminary studies showed that five sessions, but not one, was sufficient to trigger a significant antidepressant-like response on the FST (Supplementary Figure S1).

\section{Pharmacological Antidepressants}

The following drugs were administered by intraperitoneal (i.p.) injection. Imipramine $20 \mathrm{mg} / \mathrm{kg}$ (Sigma-Aldrich, St Louis, MO) was dissolved in saline and administered daily for 22 days. The TST was run $1 \mathrm{~h}$ after treatment on day 21 , followed approximately $2 \mathrm{~h}$ later by a pre-test FST. The FST was carried out $1 \mathrm{~h}$ after injection on day 22 . Ketamine $10 \mathrm{mg} / \mathrm{kg}$ (Sigma-Aldrich) was dissolved in saline and administered once. The mice were subjected to an FST pre-test $2 \mathrm{~h}$ later. The TST and FST were performed the next day, approximately 23 and $29 \mathrm{~h}$ after treatment, respectively. Fluoxetine $20 \mathrm{mg} / \mathrm{kg}$ (Santa Cruz Biotechnology, Santa Cruz, CA) was dissolved in $1 \%$ dimethyl sulfoxide in saline and administered daily for 29 days. The TST and FST were run as for imipramine.

\section{Forced Swim Test}

The FST (Porsolt et al, 1977a,b) was performed by placing each animal in a glass cylindrical container filled with water (maintained at $24 \pm 1^{\circ} \mathrm{C}$ ) at a depth of $20 \mathrm{~cm}$ to ensure the animals could not rest their tails or hindpaws on the floor of the container. A large, $21 \mathrm{~cm}$-diameter container was used, as larger swimming areas may provide greater sensitivity to antidepressant-like effects on the FST (Sunal et al, 1994). Water was changed between mice. Twenty-four hours after the last ECS, animals were each exposed to a 10-min 'pre-test' swim. After the pre-test swim, mice were dried with paper towels, placed in a warming chamber for $15 \mathrm{~min}$, and returned to their home cages. After an additional $24 \mathrm{~h}$, mice were exposed to a $6 \mathrm{~min}$ swim which was videotaped from a top-view camera angle. Videos were manually scored for immobility by two independent raters blind to genotype and treatment using the computer program Hindsight v.1.5. Immobility times were determined for the last $4 \mathrm{~min}$ of the 6-min swim session (Porsolt et al, 1978, 2001). Immobility times were averaged between both raters. In the event the raters' scores differed by more than $15 \%$ for a particular mouse, a third rater scored the video and an average across the three reviewers was used for analysis. Different cohorts were used for the forced swim, tail suspension and open field (see below) tests.

\section{Tail Suspension Test}

In unstressed mice, the TST was performed approximately $24 \mathrm{~h}$ after the last ECS. In stressed mice, the TST was run $48 \mathrm{~h}$ after the last ECS. A full description of experiments utilizing stressed mice can be found in Supplementary Materials. The TST (Steru et al, 1985) was performed by suspending mice for 6 min about 12 inches in the air using adhesive tape to fix the end of their tails to a metal frame. Tests were videotaped and scored as described for the FST, except that immobility scores were determined for the entire $6 \mathrm{~min}$ of the test (Porsolt et al, 2001; Steru et al, 1985).

\section{Open-Field Test}

Twenty-four hours after the fifth daily ECS or sham treatment, mice were subjected to a $10 \mathrm{~min}$ pre-test FST. After another $24 \mathrm{~h}$ ( $48 \mathrm{~h}$ after the last ECS or sham), locomotor activity was monitored in an open field measuring $40 \times 40 \mathrm{~cm}$. Distance traveled was measured by an infrared tracking system (Digiscan Animal Activity Monitor, Accuscan Instruments Inc, Columbus, Ohio) over a $30 \mathrm{~min}$ time period.

\section{Immunohistochemistry}

Cell markers of neuronal activity, proliferation, and maturation were monitored following the 5-day ECS regimen. For analyses of c-Fos neuronal activation following ECS, mice were killed $1 \mathrm{~h}$ after the last ECS. To monitor the rate of cell division triggered by ECS, mice were injected with BrdU (B5002; Sigma, St Louis, MO; $50 \mathrm{mg} / \mathrm{kg}$ i.p.) every $12 \mathrm{~h}$ for 5 days beginning on day 3 of the ECS course, and killed $12 \mathrm{~h}$ after the last BrdU injection. Finally, for morphological analyses of newly born doublecortin-positive cells, animals were killed $24 \mathrm{~h}$ after the last ECS treatment. For all these experiments, animals were anesthetized with chloral hydrate 
(C8383; Sigma; $400 \mathrm{mg} / \mathrm{kg}$ i.p.) prior to perfusion with $4 \%$ paraformaldehyde (P6148; Sigma). Brains were maintained in $4 \%$ paraformaldehyde overnight, and subsequently transferred to $25 \%$ sucrose.

Sections were processed for immunohistochemistry as previously described (Reti and Baraban, 2003). Primary antibodies were: rabbit anti-c-Fos (1:1000; PC05; Millipore, Billerica, MA), mouse anti-BrdU (1 : 100; B8434; Sigma), and goat anti-doublecortin (DCX; 1:250; SC8066; Santa Cruz Biotechnology, Santa Cruz, CA).

\section{Cell Counting}

Stained cells were counted by two raters who were blind to genotype and treatment, and the areas used for counting were the same size across all animals for each region. Digital images were captured at six representative coronal sections containing each brain region of interest. For c-Fos and BrdU quantification, images were visualized and captured with a Zeiss microscope fitted with a Retiga 2000R camera (QImaging, Surrey, BC Canada). For c-Fos quantification, we selected sections through the basolateral amygdala (BLA), dentate gyrus, NAc shell, NAc core, ventromedial hypothalamus (VMH), and medial prefrontal cortex (mPFC), located approximately $-1.34,-2.30,1.42,1.42,-1.70$, and $2.10 \mathrm{~mm}$ from bregma, corresponding to plates 42, 50, 19, 19, 46, and 14, respectively, of the Paxinos and Franklin mouse brain atlas (Paxinos and Franklin, 2001). For BrdU and DCX analyses, cell counts were limited to the dentate gyrus. Reported BrdU-positive cell counts were normalized by the cumulative average for sham-treated WT mice. For quantification of DCX-positive cells, we used stereological optical fractionation at $\times 100$ magnification from multiple sample frames of $40 \mu \mathrm{m} \times 40 \mu \mathrm{m}$ that were distributed over the delineated region of interest. Images were captured with a Zeiss AxioImager.

\section{RNA Isolation and Quantitative PCR (qPCR)}

WT and NARP KO adult male mice ( $n=4$ per genotype/ condition) were killed by cervical dislocation $90 \mathrm{~min}$ or $24 \mathrm{~h}$ after completion of the last ECS session and hippocampal tissues were collected and placed in RNAlater (ThermoFisher). Total RNA was isolated and extracted using TRIzol (Life Technologies, Carlsbad, CA). RNA was subsequently purified using an RNeasy minicolumn (Qiagen, Valencia, CA) and quantified using a NanoDrop spectrophotomer (Agilent Technologies, Savage, MD). RNA concentration was normalized and reverse transcribed into single stranded cDNA using Superscript III (Life Technologies). Quantitative PCR was performed using a Realplex thermocycler (Eppendorf, Hamburg, Germany) using GEMM mastermix (Life Technologies) with $40 \mathrm{ng}$ of synthesized cDNA. PCR efficiencies of $B d n f$ primers were examined by standard curve of serial-diluted cDNA and melting-curve functionality (Maynard et al, 2016; Sakata et al, 2009). Individual mRNA levels were normalized for each well to Gapdh mRNA levels.

\section{Hippocampal BDNF Levels}

BDNF protein assays were conducted as described previously (Matsumoto et al, 2008). Briefly, mice were killed by decapitation $24 \mathrm{~h}$ after the fifth daily ECS or sham treatment, when BDNF levels have been shown to reach maximal levels following repeated ECS (Altar et al, 2003). Hippocampi were then dissected and flash-frozen in a 50:50 mixture of isopentane and dry ice. Hippocampal samples were subsequently homogenized in $1.5 \mathrm{ml}$ of RIPA buffer (50 mM Tris$\mathrm{HCl}$ (pH7.5), $150 \mathrm{mM} \mathrm{NaCl}, 5$ mM EDTA, 1\% Triton-X 100, $1 \% \mathrm{Na}$ deoxycholate, and $0.1 \%$ SDS) containing $4 \%$ protease inhibitor cocktail (complete, Mini; Roche Diagnostics Corp., Indianapolis, IN). Tissue lysates underwent immunoprecipitation with monoclonal mouse anti-BDNF antibody $(1 \mu \mathrm{g} /$ sample; BDNF-\#9; Developmental Studies Hybridoma Bank, Iowa City, IA) bound to protein $\mathrm{G}$ beads ( $10 \mu \mathrm{l} /$ sample; 10003D; Thermo Fisher Scientific, Waltham, MA), and final purified samples were solubilized and boiled for $2 \mathrm{~min}$ in $30 \mu \mathrm{l}$ Laemmli solution containing 5\% $\beta$-Mercaptoethanol. Non-precipitated sample lysates were saved in the same manner to normalize total protein levels across samples.

Protein samples were resolved by electrophoresis using 4$12 \%$ gradient SDS-polyacrylamide gels and then transferred to nitrocellulose membranes. For western blotting, membranes were blocked in $0.05 \%$ Tween 20 in Tris-buffered saline containing 5\% non-fat milk and $1 \times$ Protein G blocker (M01014; Genscript, Piscataway, NJ). Membranes were then incubated at $4{ }^{\circ} \mathrm{C}$ overnight in either polyclonal rabbit antiBDNF (1:200; SC546; Santa Cruz Biotechnology, Santa Cruz, CA), or monoclonal rabbit anti-ERK (1 : 1000; \#4695; Cell Signaling Technology, Danvers, MA), followed by overnight incubation with horseradish peroxidaseconjugated donkey anti-rabbit IgG antibody (NA934; GE Healthcare Life Sciences, Marlborough, MA) at room temperature. The signals were visualized using an electrochemiluminescence system (ECL; RPN2232; GE Healthcare Life Sciences).

Quantification of raw signal intensities was conducted using Image J software (Schindelin et al, 2015). Raw intensity values for pro- and mature-BDNF signals were sequentially normalized for: (1) protein levels, using the ERK signal intensity of each individual sample, and (2) comparisons to WT sham levels using the average intensity of the WT sham samples in the same film.

\section{DCX-positive Dendritic Outgrowth}

DCX-positive dendritic outgrowth in the suprapyramidal blade of the dentate gyrus was quantified in mice killed $24 \mathrm{~h}$ following five consecutive days of ECS. For each animal, $5 \mu \mathrm{m}$-thick $\mathrm{z}$-stack projections were obtained using the Zeiss Axiovision extended focus module from three representative coronal sections corresponding to $-1.82,-2.06,-2.30 \mathrm{~mm}$ from bregma (Paxinos and Franklin, 2001) Images were captured with a Zeiss AxioImager M2.

A simplified Sholl analysis was used to analyze the extent of dendritic growth towards the hippocampal fissure. We conducted our analyses at the midpoint of the molecular layer, where projection fibers from the entorhinal cortex terminate upon the DCX-positive dendrites that extend into the outer molecular layer. Thus, for each coronal section analyzed, we quantified the number of dendritic intersections crossing the midline of the molecular layer for the entire suprapyramidal blade of the dentate gyrus in the manner outlined below. 
Using MCID Core Software (Focus Imaging Ltd, Linton, $\mathrm{UK})$, relative optical density (ROD) profiles were obtained along the midline of the molecular layer and the granule cell layer. Scanning across the midline of these layers, the line of analysis was largely composed of low amplitude ROD values corresponding to background staining, with only intermittent spikes corresponding to true DCX-positive dendritic intersections. Therefore, the weighted mean ROD for each section roughly corresponded to the threshold intensity between signal and noise. However, we chose a more conservative signal threshold obtained by adding three times the standard deviation of the ROD values for sham-treated WT mice to the weighted mean ROD value. Since shamtreated WT mice represent the 'baseline' minimum for dendritic intersections at the midpoint of the molecular layer, the range of their ROD values also provided the most consistent standard deviation value to adjust the threshold. Although it would have been more straightforward to use each individual section's ROD standard deviation, this would have preferentially raised the threshold for ECS-treated WT mice (which have more dendritic crossings) to more conservative values. Following signal binarization, the number of discrete dendritic intersections were counted and divided by the total width of molecular layer segment analyzed. The described thresholding algorithm yielded $92 \%$ accuracy compared with manual counts (data not shown).

\section{Statistical Methods}

Data were analyzed using two-way analysis of variances (ANOVAs). When appropriate, post hoc analyses were performed using Bonferroni or Fisher's least significant difference test. All values are expressed as means \pm SEM. $p$-values $<0.05$ were considered statistically significant.

\section{RESULTS}

\section{Narp Deletion Blocks Antidepressant-Like Effects of ECS in FST and TST}

Consistent with our hypothesis, Narp KO mice fail to show reduced immobility following ECS compared to sham controls in the FST. In contrast, WT mice display the expected reduction in immobility in this assay in response to ECS (Figure 1a; two-way ANOVA shows a significant interaction between genotype and treatment: $\mathrm{F}(1$, $35)=5.08, p=0.031$; post hoc analysis of WT sham vs ECS groups, $p=0.002$; Narp KO sham $v s$ ECS groups, $p=0.63$ ).

Analysis of the TST data yielded a similar pattern of results as WT, but not Narp KO, mice show reduced immobility following ECS treatment (Figure 1b; two-way ANOVA shows a significant interaction between genotype and treatment: $\mathrm{F}(1,37)=7.83, p=0.00813$; post hoc analysis of WT sham $v s$ ECS groups, $p<0.0001$; Narp KO sham $v s$ ECS groups, $p=0.67$ ). In pilot studies, we found that CF-1 mice do not show reduced sucrose preference following chronic stress precluding us from using this assay to compare the antidepressant-like effects of ECS in WT and KO mice. However, as reported above for naïve mice, in stressed mice, Narp deletion blocked the ability of ECS to decrease immobility in the TST observed in WT mice (Supplementary Figures S2).
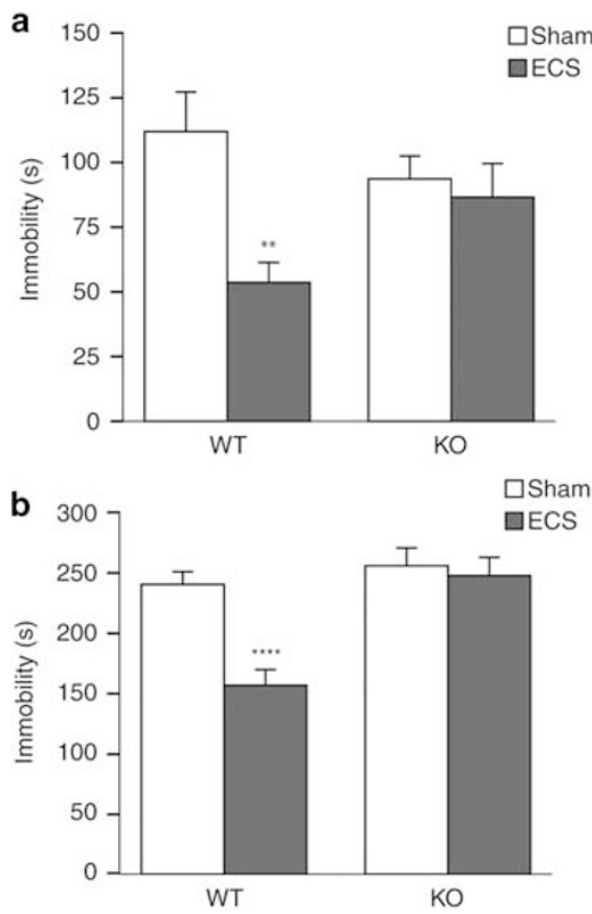

Figure I Effect of ECS on the FST (a) and TST (b) in Narp KO and WT mice. The ability of ECS to decrease immobility scores in both the FST and TST is blocked by Narp deletion. Two-way ANOVAs showed a significant interaction between genotype and treatment on immobility in the FST $(p<0.05, n=8-12$ in each group) and the TST $(p<0.01, n=|0-1|$ in each group). Comparison of sham vs ECS-treated WT mice in FST and TST, *** $p<0.01$ and $* * * * *<<0.0001$, respectively (Fisher's post hoc test). Bars represent means $( \pm$ SEM) in this and subsequent figures. ECS, electroconvulsive seizures; FST, forced swim test; TST, tail suspension test; $\mathrm{KO}$, knockout; WT, wild-type; ANOVA, analysis of variance.

\section{Narp KO Mice Display Normal Electrically Induced Seizure Activity}

Seizure duration. As these behavioral results indicate that Narp deletion blocks the antidepressant-like effects of ECS, we proceeded to check whether it may do so by impairing the ability of electric stimuli to elicit seizure activity. Accordingly, we compared ECS-induced seizure duration in WT and Narp KO mice.

Evidence from human studies suggests that seizure duration can play a role in the efficacy of ECT (Kimball et al, 2009). However, seizure duration was unchanged in Narp KO mice (Figure 2a; two-way repeated measures ANOVA showed no effect of genotype: $F(1,8)=0.49$, $p=0.831$, nor an interaction between genotype and treatment: $\mathrm{F}(4,32)=0.56, p=0.69)$.

c-Fos induction. To gauge whether Narp deletion may impair seizure activity per se, we also assessed whether it affects several responses to ECS: induction of c-Fos, increased locomotor activity, enhanced hippocampal neurogenesis and BDNF induction. Analysis of the number of c-Fos-positive cells in multiple brain regions did not reveal any effect of Narp deletion (Figure 2b). Two-way ANOVA revealed a main effect of treatment on c-Fos induction in the BLA $(\mathrm{F}(1,15)=35.98$, $p<0.0001)$, dentate gyrus $(\mathrm{F}(1,16)=28.54, p<0.0001)$, NAc (shell only) $(\mathrm{F}(1,14)=5.23, p=0.038), \operatorname{VMH}(\mathrm{F}(1,15)=106.32$, 


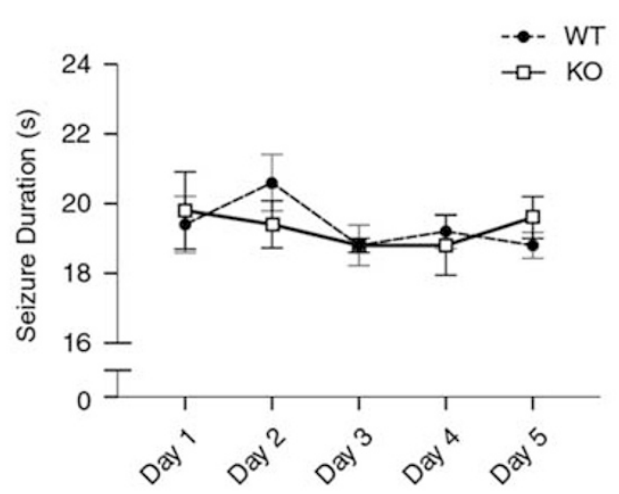

C

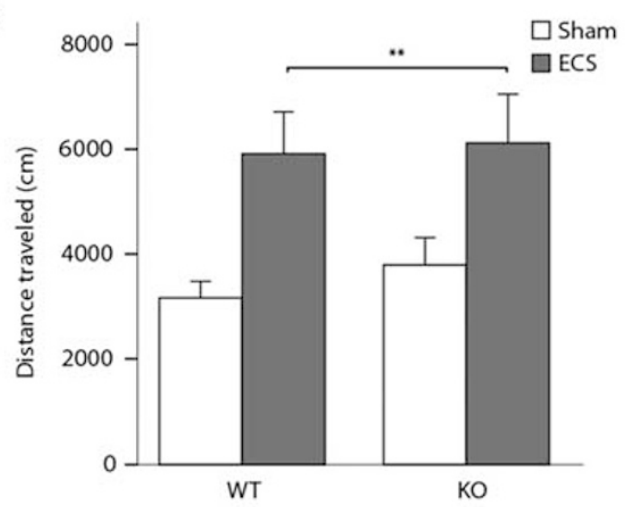

e
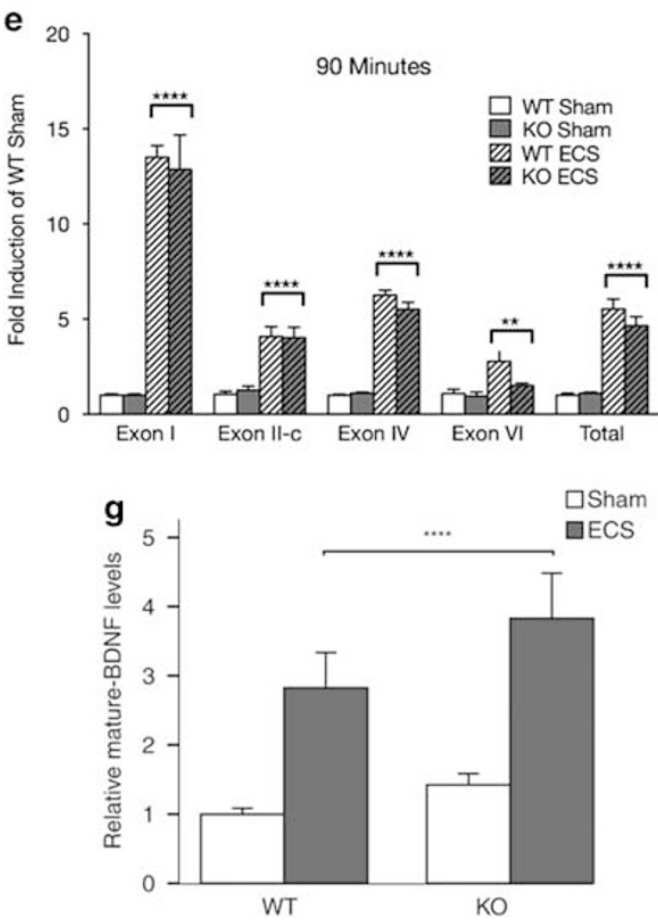

$p<0.0001)$ and $\operatorname{mPFC}(\mathrm{F}(1,16)=12.04, p=0.003)$. In all areas except the core of the NAc, ECS resulted in an increase in c-Fos-positive cells. There was no interaction between genotype b

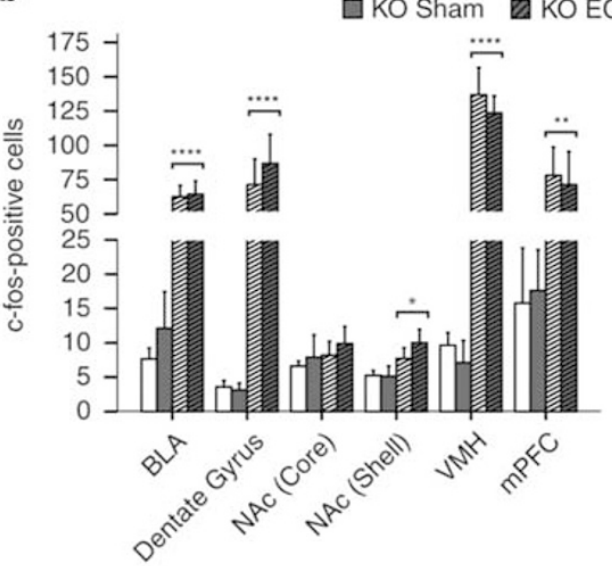

d

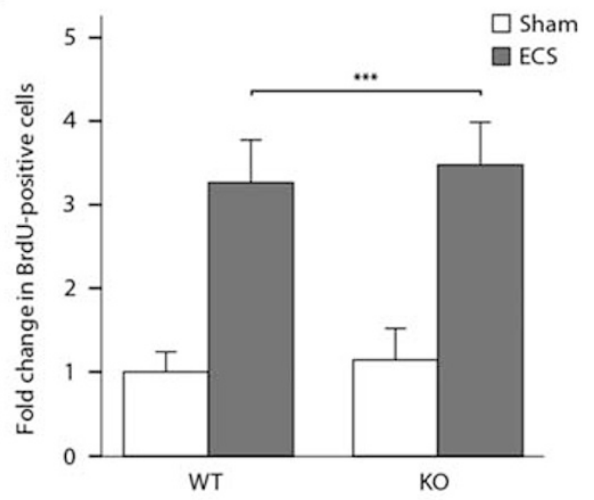

f

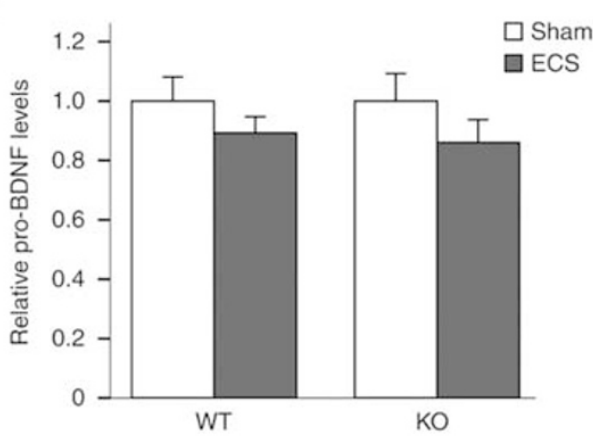

and treatment in this experiment for any of the brain regions examined, suggesting that ECS produces equivalent activation of neurons in Narp KO and WT mice. 


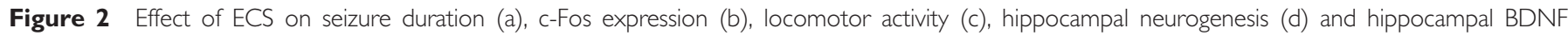

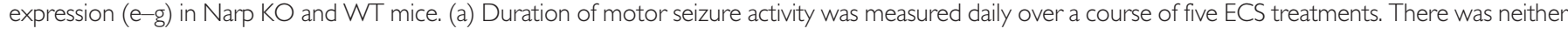

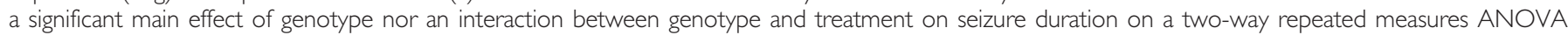

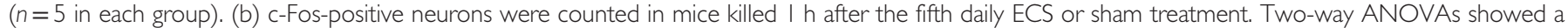

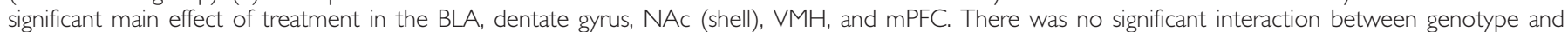

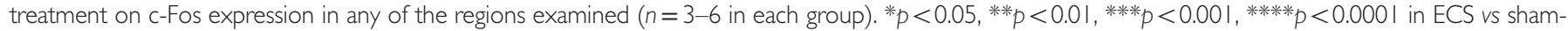

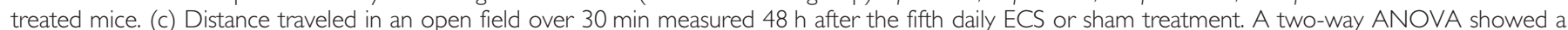

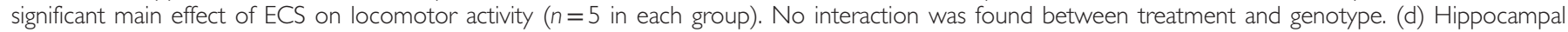

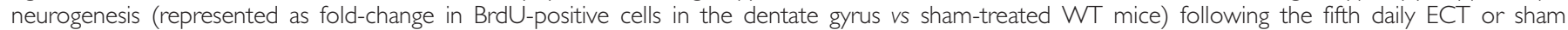

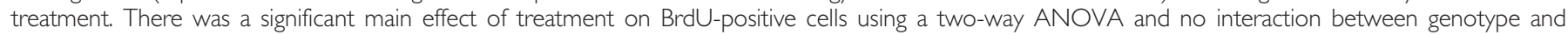

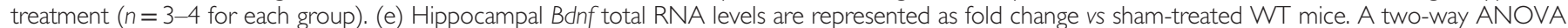

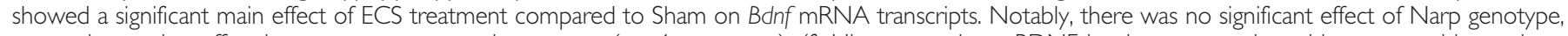

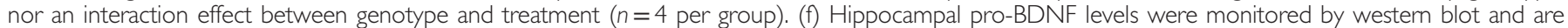

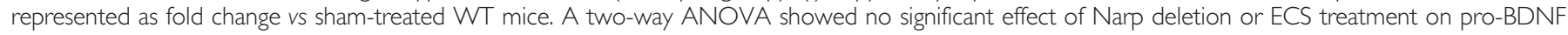

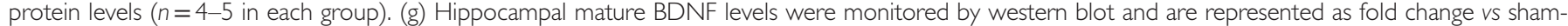

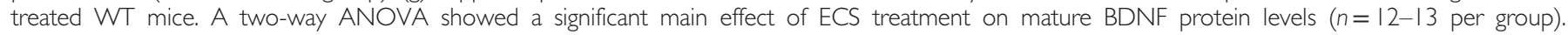

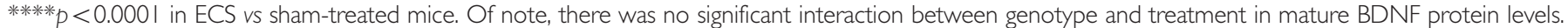

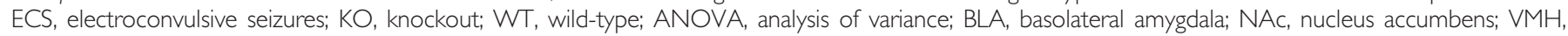
ventromedial hypothalamus; mPFC, medial prefrontal cortex; ECT, electroconvulsive therapy.

Locomotor activity. ECS increases locomotor activity in rodents (Li et al, 2006). Therefore, it is conceivable that if Narp deletion alters the impact of ECS on locomotor activity, this differential effect could potentially confound the interpretation of the FST and TST results reported above. However, by two-way ANOVA we found no interaction between genotype and treatment on locomotor activity $(\mathrm{F}(1$, $16)=0.96, p=0.76$, Figure 2c), although there was an expected significant main effect of treatment $(\mathrm{F}(1$, $16)=13.84, p=0.002$ ), such that both $\mathrm{WT}$ and $\mathrm{KO}$ mice display similar increases in locomotor activity following ECS compared to sham-treated controls.

Hippocampal neurogenesis. Hippocampal neurogenesis has been shown to be necessary for the antidepressant response to chemical antidepressants in rodents (Santarelli et al, 2003). Accordingly, we checked whether Narp deletion might impair the ability of ECS to increase hippocampal neurogenesis. Analysis of BrdU-positive cells by two-way ANOVA revealed a main effect of treatment $(\mathrm{F}(1$, $10)=24.33, p<0.001)$ showing that mice given ECS had a significant increase in neurogenesis compared to shamtreated mice (Figure 2d). However, there was no significant interaction of genotype and treatment $(\mathrm{F}(1,10)=0.005$, $p=0.94)$, suggesting that Narp deletion does not impair stimulation of hippocampal neurogenesis by ECS.

Hippocampal BDNF. As these studies thus far indicate that the ability of Narp deletion to block antidepressant-like effects of ECS occurs in the face of normal levels of seizure activity, we proceeded to check whether Narp deletion might impair the ability of ECS to induce hippocampal BDNF, a neurotrophic factor that has been strongly implicated in mediating therapeutic effects of antidepressant drugs (Hashimoto et al, 2004; Castren and Rantamaki, 2010a). Transcription of $B d n f$ is controlled by nine promoters, which drive expression of multiple transcripts containing alternative 5' untranslated exons (Timmusk et al, 1993; Aid et al, 2007). Promoters I, II, IV, and VI produce the majority of BDNF in the brain, and promoters I and IV contribute significantly to activity-dependent BDNF transcription (Aid et al, 2007; Pruunsild et al, 2007). Analysis of Bdnf transcripts derived from promoters I, II, IV and VI as well as total Bdnf mRNA in WT and Narp KO hippocampus collected $90 \mathrm{~min}$ after the last treatment session revealed a main effect of treatment for all $B d n f$ transcripts analyzed (Figure 2e; two-way ANOVAs; Exon I: $\mathrm{F}(1,12)=162.3$, $p<0.0001$; Exon II: $\mathrm{F}(1,12)=54.93, p<0.0001$; Exon IV: $\mathrm{F}$ $(1,12)=440.9, \quad p<0.0001 ; \quad$ Exon VI: $\mathrm{F}(1,12)=9.501$, $p=0.0095$; Total Bdnf: $\mathrm{F}(1,12)=126.5, p<0.0001)$. However, there were no interactions of genotype and treatment indicating that ECS induces similar elevations in $B d n f$ transcription in WT and Narp KO. We also examined $B d n f$ mRNA levels at $24 \mathrm{~h}$ after the last treatment session and found a similar persistence in the elevation of activityinduced Bdnf promoters I and II between WT and NARP KO mice (Supplementary Figure S4).

As BDNF transcription and translation are distinctly regulated (Lau et al, 2010), we also checked the effect of Narp deletion on BDNF protein levels in response to ECS. Moreover, given data suggesting that pro-BDNF is capable of facilitating hippocampal long-term depression (Woo et al, 2005), we assayed protein levels of pro- and mature-BDNF independently. Following $24 \mathrm{~h}$ after the last sham or ECS treatment, pro-BDNF protein levels remained identical across all WT and Narp KO mice treated in either condition (Figure 2f). Nonetheless, both the WT and Narp KO mice treated with repeated ECS exhibited a comparable two-fold increase in mature-BDNF protein levels compared to the levels of sham-treated mice (Figure 2g; two-way ANOVA shows a significant treatment effect: $\mathrm{F}(1,44)=24.88$, $p=0.00001)$, but no effect of genotype nor a genotype $\times$ treatment interaction. These results were confirmed by immunohistochemistry on WT and Narp KO transgenic mice featuring hemagglutinin (HA) epitope tagged BDNF (Yang et al, 2009). These mice exhibited comparable elevations in HA-BDNF immunoreactivity in the dentate gyrus and CA3 after repeated ECS (Supplementary Figure S4).

Narp Deletion Impairs ECS-Mediated Increase in DCX+ Dendritic Arborization in the Dentate Molecular Layer

While ECS-triggered seizure activity, including neurogenesis monitored by BrdU, appears to be intact in Narp KO mice, 
we explored whether proliferation and differentiation of neural progenitors in the hippocampal dentate gyrus were affected by Narp deletion. We stained for DCX which is a microtubule-associated protein expressed by migrating neuroblasts for around 2 weeks as the cells mature into

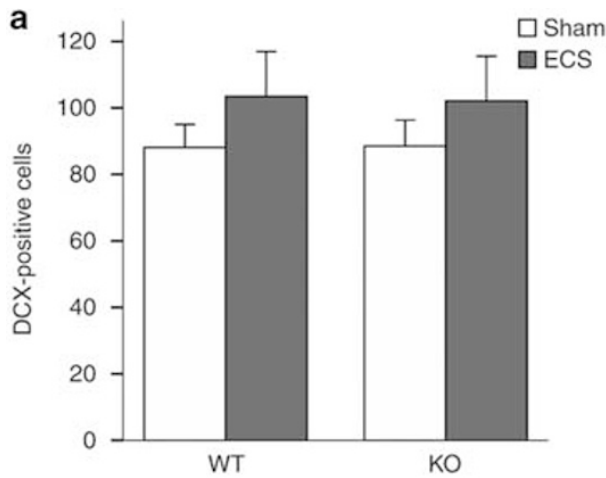

b
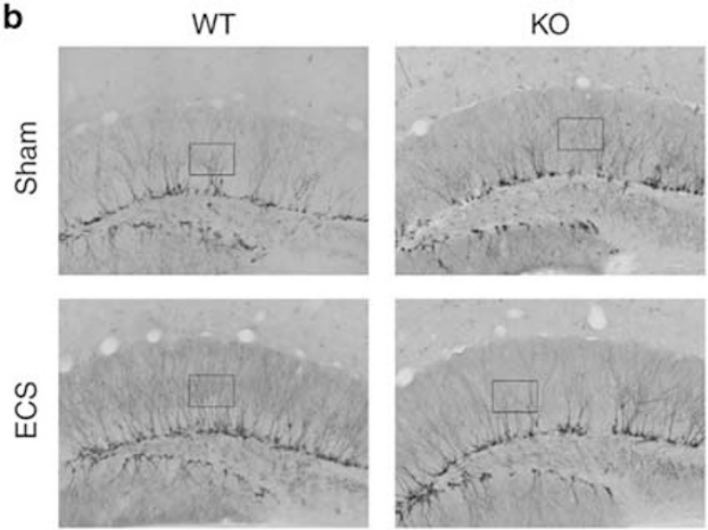

C
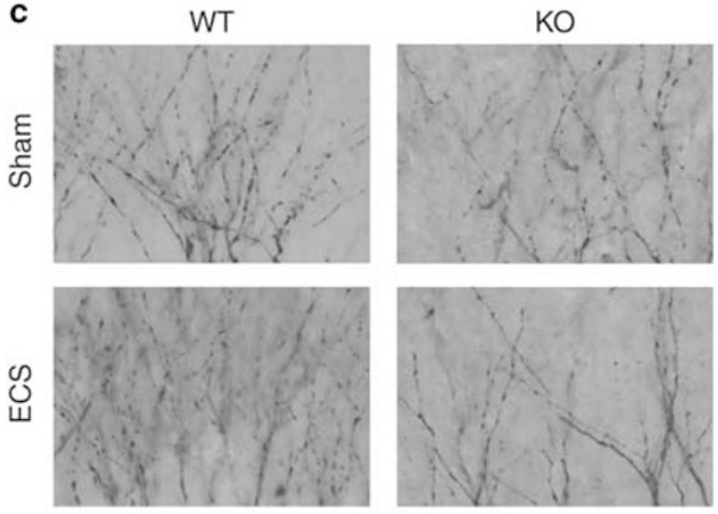

d

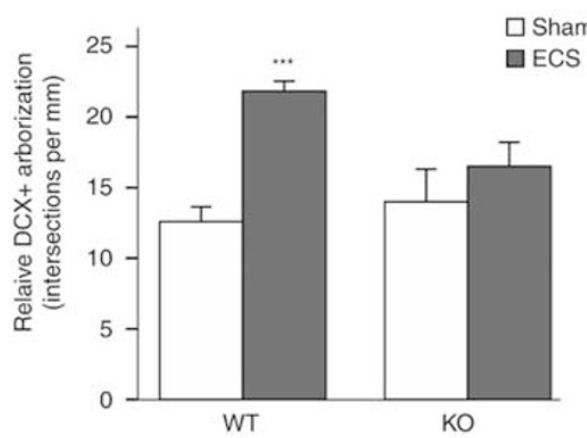

neurons (Lledo et al, 2006). We counted DCX+ dentate granule cells and monitored DCX+ dendritic outgrowth in the molecular layer in mice killed $24 \mathrm{~h}$ following five consecutive, daily ECS administrations.

Unlike the analysis of cell proliferation using BrdU, the number of DCX-positive progenitor cells was not significantly altered by either deletion of Narp or repeated ECS treatment at this time point (Figure 3a). However, we found that dendritic outgrowth beyond the midpoint of the molecular layer was markedly greater in WT mice treated with repeated ECS compared with sham; importantly, this ECS-mediated dendritic outgrowth was absent in Narp KO mice (Figure 3b-d; two-way ANOVA shows a significant interaction between genotype and treatment: $\mathrm{F}(1,20)=4.65$, $p=0.0435$; post hoc analysis of WT sham vs ECS groups, $\mathrm{p}=0.000468$; Narp KO sham $v s$ ECS groups, $p=0.273322$ ). Of note, dendritic outgrowth after ECS monitored at the mid-point of the granule cell layer was unaffected by Narp deletion (two-way ANOVA shows no interaction between genotype and treatment: $\mathrm{F}(1,24)=0.007, p=0.932$ ), although there is a main effect of treatment $(\mathrm{F}(1,24)=12.107$, $p=0.002)$ but not of genotype $(\mathrm{F}(1,24)=0.003, p=0.957)$. These data indicate Narp deletion does not influence DCX+ proximal dendritic outgrowth triggered by ECS.

\section{Narp KO Mice Respond to Chemical Antidepressants}

To determine if Narp deletion selectively affects the antidepressant response to ECS, we also tested its effects on several pharmacologic antidepressants. We monitored the effect of Narp deletion on the antidepressant response to imipramine (Figure $4 \mathrm{a}$ and b), fluoxetine (Figure $4 \mathrm{c}$ and $\mathrm{d}$ ), and ketamine (Figure $4 \mathrm{e}$ and $\mathrm{f} ; \mathrm{Li}$ et al, 2012). Consistent with previous reports that the ability of chemical antidepressants to elicit decreased immobility in the FST and TST paradigms varies among mouse strains (Lucki et al, 2001; Jacobson and Cryan, 2007), we found that WT CF-1 mice only displayed decreased immobility in either of these paradigms for two of these drugs: imipramine reduced

Figure 3 Narp modulates ECS-mediated DCX+ dendritic arborization in the molecular layer of the hippocampal dentate gyrus: (a) DCX+ cell count; (b) representative images of immunohistochemistry showing the distribution of DCX+ neurons and dendrites in the dentate gyrus; (c) representative images of inset DCX+ dendrites in the dentate gyrus; (d) DCX+ dendritic branching in the molecular layer of the dentate gyrus. (a) DCX+ cell counts were obtained within the granule layer of the dentate gyrus of WT and Narp KO mice killed $24 \mathrm{~h}$ after the fifth daily ECS or sham treatment. Twoway ANOVAs showed no significant main effects of either genotype or treatment ( $n=6$ in each group). (b) Representative histological images of $\mathrm{DCX}+$ immunohistochemistry staining in the hippocampal dentate gyrus for each category of genotype and treatment. Square insets are shown enlarged in (c). (c) Higher resolution representation of DCX + dendrite distribution in the molecular layer of the hippocampal dentate gyrus. (d) The extent of $\mathrm{DCX}+$ dendrite branching was quantified at the middle of the molecular layer of the hippocampal dentate gyrus ( $n=12$ per group). Two-way ANOVA showed a significant main effect of treatment, as well as a significant interaction effect between genotype and treatment. Of note, posthoc analysis with Fisher's LSD showed a significant difference in WT mice treated with either sham or ECS, but no corresponding difference in Narp $\mathrm{KO}$ mice. ${ }^{* * *} p<0.001$ in ECS vs sham-treated WT mice. ECS, electroconvulsive seizures; WT, wild-type; $\mathrm{KO}$, knockout; LSD, least significant difference. 
Forced swim test

a

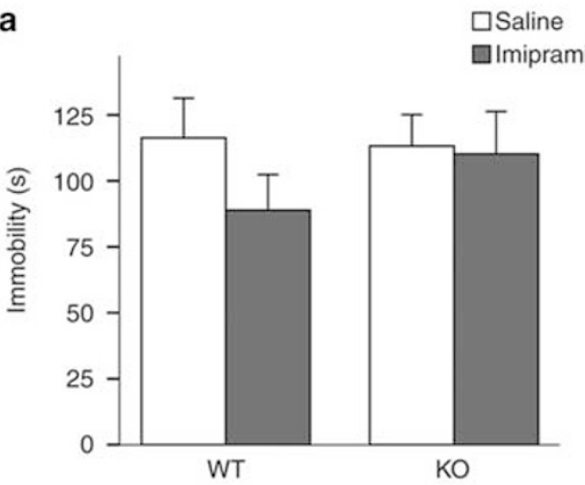

C

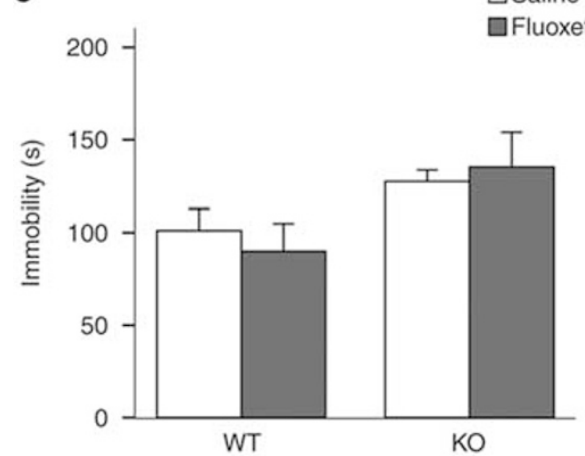

e

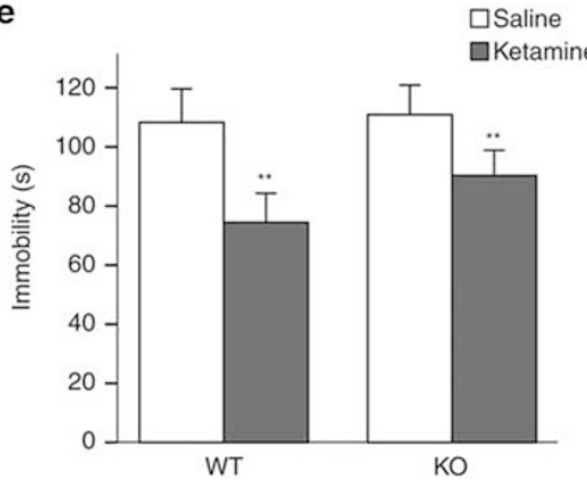

Tail suspension test

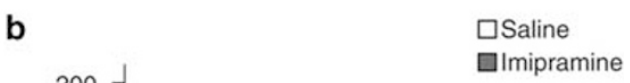

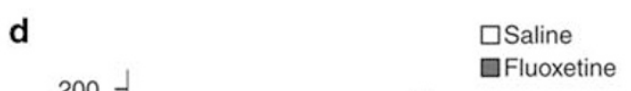

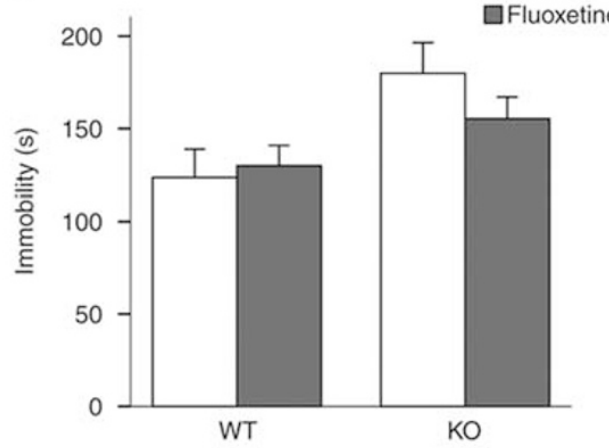

f
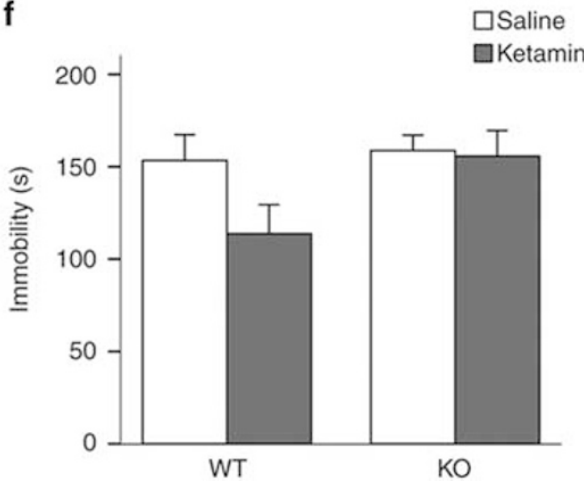

Figure 4 Effects of imipramine, fluoxetine, and ketamine on the FST and TST in Narp KO and WT mice. Immobility was scored during the last 4 min of a 6 min FST and over the entire 6 min TST. Imipramine (a,b) was administered at $20 \mathrm{mg} / \mathrm{kg}$ daily for 22 days and the TST and FST were performed 60 min following drug administration on days 21 and 22, respectively. Fluoxetine (c,d) was administered at $20 \mathrm{mg} / \mathrm{kg}$ daily for 29 days and the TST and FST were performed 60 min following drug administration on days 28 and 29, respectively. Ketamine (e,f) was administered only once at 10 mg/kg, with the TST and FST taking place approximately 23 and $29 \mathrm{~h}$ later, respectively. Two-way ANOVAs did not reveal an interaction between genotype and treatment in any of the cohorts $(n=9-14$ in each group) but showed a main effect of treatment in the TST for mice treated with imipramine and in the FST for mice treated with ketamine. *** $<0.0$ I, ******* $p<0.000$ I vs saline-treated mice. FST, forced swim test; TST, tail suspension test; KO, knockout; WT, wild-type.

immobility on the TST; ketamine reduced immobility on the FST; fluoxetine did not affect either test. In both these informative cases, Narp KO mice displayed the same response as WT mice. In the imipramine cohort, two-way ANOVAs did not show any significant interaction of genotype and treatment in the TST $(F(1,40)=0.42$, $p=0.52$ ). However, there was a significant main effect of treatment on immobility in the TST, whereby mice that received chronic imipramine had significantly less immobility compared to saline-treated controls $(\mathrm{F}(1,40)=35.26$, $p<0.0001)$. In the ketamine cohort, a two-way ANOVA showed that there was a significant main effect of ketamine on the FST $(\mathrm{F}(1,49)=7.39, p=0.009)$, with no interaction of genotype and treatment $(\mathrm{F}(1,49)=0.43, p=0.51)$.

\section{DISCUSSION}

In studies aimed at assessing whether Narp, which is induced by ECS, mediates its antidepressant actions, we have found that Narp deletion blocks the antidepressant-like behavioral effects of ECS. In particular, Narp KO mice fail to show the expected immobility reduction in the TST and FST after 
ECS. In theory, these deficits could be due to the inability of Narp KO mice to mount a normal seizure in response to electroconvulsive stimulation. However, we have found that multiple responses elicited by seizure activity, including hippocampal neurogenesis and locomotor activity, as well as induction of c-Fos and BDNF are normal in Narp KO mice. Thus, these findings provide compelling evidence that Narp deletion blocks the ability of ECS to elicit an antidepressant effect without inhibiting seizure activity.

To assess whether Narp deletion selectively blocks the antidepressant effect of ECS or also impairs the action of antidepressant drugs, we examined the effects of fluoxetine, imipramine, and ketamine on FST and TST in Narp KO mice. Unfortunately, these drugs only had limited effectiveness in reducing immobility in these assays in CF-1 WT mice. However, Narp deletion did not impair any of the antidepressant-like responses displayed by these mice, that is, imipramine on TST and ketamine on FST, indicating that Narp deletion selectively blocks the antidepressant response elicited by ECS. We did not evaluate whether Narp deletion impacts the antidepressant response to voluntary exercise. Sleiman et al (2016) demonstrate that voluntary exercise triggers activity at multiple BDNF promoters. Because Narp deletion regulates BDNF-mediated plasticity at the mossy fiber-CA3 synapse (Mariga et al (2015); see below), it is conceivable that Narp might play a role in the antidepressant effect of voluntary exercise.

Since BDNF is known to play a key role in mediating antidepressant responses (Castren and Rantamaki, 2010a), we have carefully evaluated whether Narp KO mice display deficits in BDNF induction elicited by ECS. To this end, we monitored expression of multiple BDNF transcripts, as well as mature and pro-BDNF proteins. However, none of these assays revealed a genotype $\times$ treatment abnormality. On the other hand, Mariga et al (2015) reported bi-directional regulation of Narp by BDNF, and that BDNF directly regulates Narp to mediate glutamatergic transmission and mossy fiber plasticity. Taken together, these findings suggest that Narp deletion does not impair BDNF induction by ECS, but could interfere with its downstream effects.

Like BDNF, hippocampal neurogenesis has also been implicated in mediating antidepressant responses to both ECS and chemical agents (Santarelli et al, 2003; Schloesser et al, 2015). Utilizing a pharmacogenetic model (hGFAPtk) to conditionally ablate adult-born neurons, Schloesser et al (2015) recently found that ECS was unable to promote antidepressant-like behavior in mice lacking adult neurogenesis. In our study, we found comparable increases in the number of BrdU labeled cells in the dentate gyrus of WT and Narp KO mice after ECS, suggesting that Narp does not affect ECS-induced increases in neurogenesis. The lack of increase in DCX+ cell number that we found 5 days after initiating ECS likely reflects insufficient time for the total number of DCX+ cells to be impacted by the increased number of new progenitor cells triggered by ECS. Although the number of DCX+ neurons was unaffected in Narp KO mice, the ability of ECS to increase their dendritic arborization was blocked. Therefore, our data suggest that the enhanced hippocampal neurogenesis induced by ECS is not sufficient to mediate the rapid antidepressant action of ECS but must be coupled with increased arborization of $\mathrm{DCX}+$ granule cell neurons.
Since Narp is not present in DCX+ neurons (Supplementary Figure S5) and is secreted from nerve terminals (O'Brien et al, 1999), we hypothesize that its role in mediating ECS-induced dendritic outgrowth is due to the influence of Narp in afferents to DCX+ neurons. Detailed analysis of afferents to immature granule cells generated in adulthood has demonstrated that they receive axonal inputs from mature granule cells, which express Narp (Vivar and van Praag, 2013). In addition, Narp is robustly expressed in the entorhinal cortex (Oh et al, 2014), which sends projections to the dentate molecular layer via the perforant pathway. Narp secreted by these projections could promote dendritic outgrowth as previous studies have shown that recombinant Narp enhances growth of dendritic processes of neurons of cortical explants (Tsui et al, 1996a). However, it is also conceivable that the observed effects on DCX+ dendritic arborization could reflect indirect effects of Narp on dentate gyrus excitability. As reviewed in Ikrar et al (2013), dentate granule cells demonstrate feedback inhibition via the mossy fiber-CA3-hilar interneuron circuit which could be disrupted by Narp deletion as Narp is trafficked along mossy fibers after ECS (Reti and Baraban, 2000; O’Brien et al, 1999) and Narp regulates mossy fiber plasticity (Mariga et al, 2015).

Since the ability of ECS to elicit antidepressant-like effects is dependent on adult hippocampal neurogenesis (Schloesser et al, 2015), it is tempting to speculate that the increased dendritic arborization induced by ECS also plays a critical role. Then, the ability of Narp deletion to abolish the behavioral antidepressant effects of ECS could reflect its blockade of these morphological changes elicited by ECS. However, further studies are needed to test this hypothesis. The availability of conditional Narp KO mice would be particularly helpful in identifying which Narp-positive afferents mediate the ability of ECS to increase dendritic arborization of DCX+ neurons and if these play an essential role in eliciting the antidepressant response to ECS. In addition, further studies employing retroviral labeling of newborn granule cells and their afferents are warranted to confirm the effects observed on dendritic morphology using DCX immunostaining and to determine if these changes reflect a general increase in afferent innervation or selective increases in particular afferents. Furthermore, conditional deletion of Narp would also be helpful in assessing whether Narp expression in other limbic areas (Reti et al, 2002b, c,2008a,2012) may also contribute to mediating the antidepressant effects of ECS.

We are aware that concerns about whether the TST and FST provide a reliable measure of antidepressant efficacy have fostered the use of additional behavioral assays considered to have higher face validity, such as sucrose preference and novelty-induced suppression of feeding (Nestler and Hyman, 2010). However, in preliminary studies we found that WT CF-1 mice do not exhibit reduced sucrose preference following chronic stress rendering this assay uninformative in evaluating the impact of Narp deletion on the CF-1 background. However, while it is reasonable to be skeptical of the predictive validity of these immobility assays in evaluating novel antidepressant treatments, we are using them here in a different context, that is, to assess whether Narp deletion blocks the antidepressant activity of a wellestablished and highly efficacious antidepressant treatment. 
Furthermore, we have found in pilot studies that a single ECS episode is not sufficient to reduce immobility on the FST in CF-1 mice indicating that this assay parallels the need to use multiple ECT treatments clinically.

In conclusion, as repeated seizure activity produces a bewildering array of electrophysiological and biochemical effects in brain, it has been unclear whether it would be feasible to identify which of these play a critical role in its highly effective antidepressant effects, information that would be valuable in developing improved treatment regimens. We submit that these findings provide an important starting point for deciphering the molecular basis of ECT by focusing attention on Narp, and its role in regulating dendritic outgrowth, as a potential mediator of its antidepressant action.

\section{FUNDING AND DISCLOSURE}

This work was supported by R01DA016303 (Reti), R01NS039156 (Worley), U54HD079123 (Mary E Blue), and SFARI 528708 (Stepanian). Drs Reti and Vaidya have received supplies at no cost from Neuronetics Inc. Dr Reti was and is site PI on multi-site TMS trials sponsored by Brainsway Inc and the United States Department of Defense. The remaining authors declare no conflicts of interest.

\section{ACKNOWLEDGMENTS}

We sincerely thank Eric and Alison Jager for their very generous support of this project.

\section{REFERENCES}

Aid T, Kazantseva A, Piirsoo M, Palm K, Timmusk T (2007). Mouse and rat BDNF gene structure and expression revisited. $J$ Neurosci Res 85: 525-535.

Altar CA, Whitehead RE, Chen R, Wortwein G, Madsen TM (2003). Effects of electroconvulsive seizures and antidepressant drugs on brain-derived neurotrophic factor protein in rat brain. Biol Psychiatry 54: 703-709.

Castren E, Rantamaki T (2010a). The role of BDNF and its receptors in depression and antidepressant drug action: reactivation of developmental plasticity. Dev neurobiol 70: 289-297.

Chang AD, Berges VA, Chung JS, Fridman GY, Baraban JM, Reti IM (2016). High frequency stimulation at the subthalamic nucleus suppresses excessive self-grooming in autism-like mouse models. Neuropsychopharmacology 41: 1813-1821.

Cole AJ, Abu-Shakra S, Saffen DW, Baraban JM, Worley PF (1990). Rapid rise in transcription factor mRNAs in rat brain after electroshock-induced seizures. J neurochem 55: 1920-1927.

Cryan JF, Mombereau C, Vassout A (2005). The tail suspension test as a model for assessing antidepressant activity: review of pharmacological and genetic studies in mice. Neurosci Biobehav Rev 29: 571-625.

Gebhart GF, Mitchell CL (1973). Strain differences in the analgesic response to morphine as measured on the hot plate. Arch Int Pharmacodyn 201: 128-140.

Hashimoto K, Shimizu E, Iyo M (2004). Critical role of brainderived neurotrophic factor in mood disorders. Brain Res Brain Res Rev 45: 104-114.

Husain MM, Rush AJ, Fink M, Knapp R, Petrides G, Rummans T et al (2004). Speed of response and remission in major depressive disorder with acute electroconvulsive therapy (ECT): a
Consortium for Research in ECT (CORE) report. J clin psychiatry 65: 485-491.

Ikrar T, Guo N, He K, Besnard A, Levinson S, Hill A et al (2013). Adult neurogenesis modifies excitability of the dentate gyrus. Front Neural Circuits 7: 204.

Jacobson LH, Cryan JF (2007). Feeling strained? Influence of genetic background on depression-related behavior in mice: a review. Behav Genet 37: 171-213.

Johnson AW, Crombag HS, Takamiya K, Baraban JM, Holland PC, Huganir RL et al (2007). A selective role for neuronal activity regulated pentraxin in the processing of sensory-specific incentive value. $J$ Neurosci 27: 13430-13435.

Johnson AW, Han S, Blouin AM, Saini J, Worley PF, During MJ et al (2010a). Localized disruption of Narp in medial prefrontal cortex blocks reinforcer devaluation performance. Learn mem 17: 620-626.

Kimball JN, Rosenquist PB, Dunn A, McCall V (2009). Prediction of antidepressant response in both 2.25xthreshold RUL and fixed high dose RUL ECT. J Affect Disord 112: 85-91.

Krishnan V, Nestler EJ (2008). The molecular neurobiology of depression. Nature 455: 894-902.

Lau AG, Irier HA, Gu J, Tian D, Ku L, Liu G et al (2010). Distinct 3'UTRs differentially regulate activity-dependent translation of brain-derived neurotrophic factor (BDNF). Proc Natl Acad Sci USA 107: 15945-15950.

Li B, Suemaru K, Cui R, Kitamura Y, Gomita Y, Araki H (2006). Repeated electroconvulsive stimuli increase brain-derived neurotrophic factor in ACTH-treated rats. Eur J Pharmacol 529: $114-121$.

Li X, Frye MA, Shelton RC (2012). Review of pharmacological treatment in mood disorders and future directions for drug development. Neuropsychopharmacology 37: 77-101.

Lledo PM, Alonso M, Grubb MS (2006). Adult neurogenesis and functional plasticity in neuronal circuits. Nat Rev Neurosci 7: 179-193.

Lucki I, Dalvi A, Mayorga AJ (2001). Sensitivity to the effects of pharmacologically selective antidepressants in different strains of mice. Psychopharmacology (Berl) 155: 315-322.

Mariga A, Glaser J, Mathias L, Xu D, Xiao M, Worley P et al (2015). Definition of a bidirectional activity-dependent pathway involving BDNF and Narp. Cell Rep 13: 1747-1756.

Matsumoto T, Rauskolb S, Polack M, Klose J, Kolbeck R, Korte M et al (2008). Biosynthesis and processing of endogenous BDNF: CNS neurons store and secrete BDNF, not pro-BDNF. Nature neuroscience 11: 131-133.

Maynard KR, Hill JL, Calcaterra NE, Palko ME, Kardian A, Paredes $\mathrm{D}$ et al (2016). Functional role of BDNF production from unique promoters in aggression and serotonin signaling. Neuropsychopharmacology 41: 1943-1955.

Nestler EJ, Hyman SE (2010). Animal models of neuropsychiatric disorders. Nat Neurosci 13: 1161-1169.

O'Brien RJ, Xu D, Petralia RS, Steward O, Huganir RL, Worley P (1999). Synaptic clustering of AMPA receptors by the extracellular immediate-early gene product Narp. Neuron 23: 309-323.

Oh SW, Harris JA, Ng L, Winslow B, Cain N, Mihalas S et al (2014). A mesoscale connectome of the mouse brain. Nature 508: 207-214.

Paxinos G, Franklin KBJ (2001). The mouse brain in stereotaxic coordinates2nd edn.Academic: San Diego, CA; London.

Petit-Demouliere B, Chenu F, Bourin M (2005). Forced swimming test in mice: a review of antidepressant activity. Psychopharmacology (Berl) 177: 245-255.

Porsolt RD, Bertin A, Jalfre M (1977a). Behavioral despair in mice: a primary screening test for antidepressants. Arch Int Pharmacodyn Ther 229: 327-336.

Porsolt RD, Bertin A, Jalfre M (1978). 'Behavioural despair' in rats and mice: strain differences and the effects of imipramine. Eur $J$ Pharmacol 51: 291-294. 
Porsolt RD, Brossard G, Hautbois C, Roux S (2001). Rodent models of depression: forced swimming and tail suspension behavioral despair tests in rats and mice. Curr Protoc Neurosci Chapter 8: Unit $810 \mathrm{~A}$.

Porsolt RD, Le Pichon M, Jalfre M (1977b). Depression: a new animal model sensitive to antidepressant treatments. Nature 266: 730-732.

Pruunsild P, Kazantseva A, Aid T, Palm K, Timmusk T (2007). Dissecting the human BDNF locus: bidirectional transcription, complex splicing, and multiple promoters. Genomics 90: 397-406.

Reti IM, Baraban JM (2000). Sustained increase in Narp protein expression following repeated electroconvulsive seizure. Neuropsychopharmacology 23: 439-443.

Reti IM, Baraban JM (2003). Opiate withdrawal induces Narp in the extended amygdala. Neuropsychopharmacology 28: 1606-1613.

Reti IM, Blouin A, Worley PF, Holland P, Johnson AW, Baraban JM (2012). The role of Narp in limbic system plasticity: relevance to drug abuse. ILAR J 52: 321-328.

Reti IM, Crombag HS, Takamiya K, Sutton JM, Guo N, Dinenna ML et al (2008a). Narp regulates long-term aversive effects of morphine withdrawal. Behav neurosci 122: 760-768.

Reti IM, Miskimon M, Dickson M, Petralia RS, Takamiya K, Bland $\mathrm{R}$ et al (2008b). Activity-dependent secretion of neuronal activity regulated pentraxin from vasopressin neurons into the systemic circulation. Neuroscience 151: 352-360.

Reti IM, Reddy R, Worley PF, Baraban JM (2002a). Prominent Narp expression in projection pathways and terminal fields. $J$ neurochem 82: 935-944.

Reti IM, Reddy R, Worley PF, Baraban JM (2002b). Selective expression of Narp in central vestibular pathways: dependence on sensory input. Eur J Neurosci 16: 1949-1958.

Reti IM, Reddy R, Worley PF, Baraban JM (2002c). Selective expression of Narp, a secreted neuronal pentraxin, in orexin neurons. J Neurochem 82: 1561-1565.

Rush AJ, Trivedi MH, Wisniewski SR, Nierenberg AA, Stewart JW, Warden D et al (2006a). Acute and longer-term outcomes in depressed outpatients requiring one or several treatment steps: a $\mathrm{STAR}^{\star} \mathrm{D}$ report. Am j psychiatry 163: 1905-1917.

Rush AJ, Trivedi MH, Wisniewski SR, Stewart JW, Nierenberg AA, Thase ME et al (2006b). Bupropion-SR, sertraline, or venlafaxineXR after failure of SSRIs for depression. N Engl J Med 354: $1231-1242$

Sakata K, Woo NH, Martinowich K, Greene JS, Schloesser RJ, Shen $\mathrm{L}$ et al (2009). Critical role of promoter IV-driven BDNF transcription in GABAergic transmission and synaptic plasticity in the prefrontal cortex. Proc Natl Acad Sci USA 106: 5942-5947.

Santarelli L, Saxe M, Gross C, Surget A, Battaglia F, Dulawa S et al (2003). Requirement of hippocampal neurogenesis for the behavioral effects of antidepressants. Science 301: 805-809.
Schindelin J, Rueden CT, Hiner MC, Eliceiri KW (2015). The Image J ecosystem: an open platform for biomedical image analysis. Mol reprod dev 82: 518-529.

Schloesser RJ, Orvoen S, Jimenez DV, Hardy NF, Maynard KR, Sukumar M et al (2015). Antidepressant-like effects of electroconvulsive seizures require adult neurogenesis in a neuroendocrine model of depression. Brain Stimul 8: 862-867.

Seale TW, Nael R, Basmadjian G (1996). Inherited, selective hyporesponsiveness to the analgesic action of nicotine in mice. NeuroReport 8: 191-195.

Segman RH, Shapira B, Gorfine M, Lerer B (1995). Onset and time course of antidepressant action: psychopharmacological implications of a controlled trial of electroconvulsive therapy. Psychopharmacology 119: 440-448.

Shepherd JD, Rumbaugh G, Wu J, Chowdhury S, Plath N, Kuhl D et al (2006). Arc/Arg3.1 mediates homeostatic synaptic scaling of AMPA receptors. Neuron 52: 475-484.

Sleiman SF, Henry J, Al-Haddad R et al (2016). Exercise promotes the expression of brain derived neurotrophic factor (BDNF) through the action of the ketone body $\beta$-hydroxybutyrate (Elmquist JK, ed.). eLife 5: e15092.

Steru L, Chermat R, Thierry B, Simon P (1985). The tail suspension test: a new method for screening antidepressants in mice. Psychopharmacology (Berl) 85: 367-370.

Sunal R, Gumusel B, Kayaalp SO (1994). Effect of changes in swimming area on results of 'behavioral despair test'. Pharmacol Biochem Behav 49: 891-896.

Timmusk T, Palm K, Metsis M, Reintam T, Paalme V, Saarma M et al (1993). Multiple promoters direct tissue-specific expression of the rat BDNF gene. Neuron 10: 475-489.

Torchiana ML, Stone CA (1959). Post seizure mortality following electroshock convulsions in certain strains of mice. Proc Soc Exp Biol Med 100: 290-293.

Tsui CC, Copeland NG, Gilbert DJ, Jenkins NA, Barnes C, Worley PF (1996a). Narp, a novel member of the pentraxin family, promotes neurite outgrowth and is dynamically regulated by neuronal activity. J neurosci 16: 2463-2478.

Vivar C, van Praag H (2013). Functional circuits of new neurons in the dentate gyrus. Front Neural Circuits 7: 15.

Woo NH, Teng HK, Siao CJ, Chiaruttini C, Pang PT, Milner TA et al (2005). Activation of p75NTR by proBDNF facilitates hippocampal long-term depression. Nat neurosci 8: 1069-1077.

Xiao B, Tu JC, Worley PF (2000). Homer: a link between neural activity and glutamate receptor function. Curr opin neurobiol 10: 370-374.

Yang J, Siao CJ, Nagappan G, Marinic T, Jing D, McGrath K et al (2009). Neuronal release of proBDNF. Nature neuroscience 12: $113-115$.

Supplementary Information accompanies the paper on the Neuropsychopharmacology website (http://www.nature.com/npp) 